\title{
Percursos da antropologia em Goiás
}

\author{
Nei Clara de Lima \\ Doutora em Antropologia (Universidade de Brasília) \\ Professora aposentada da Universidade Federal de Goiás \\ Goiânia, Goiás, Brasil \\ neiclara@yahoo.com.br
}

Resumo Este texto narra, do ponto de vista da memória da autora, alguns dos percursos da institucionalização da antropologia na Universidade Federal de Goiás. São dadas ênfases ao contexto histórico-cultural da emergência dos estudos antropológicos e às singularidades da disciplina no curso de Ciências Sociais.

Palavras-chave: emergência da antropologia na UFG, institucionalização da antropologia em Goiás, memórias.

\section{Para Custódia Selma Sena}

$\mathrm{E}$ ste texto tem como objetivo situar os movimentos pioneiros e alguns dos percursos da institucionalização da Antropologia na Universidade Federal de Goiás. Construído de um ponto de vista pessoal, é o registro de uma memória feita de fragmentos de minhas lembranças dos tempos de estudante de Ciências Sociais, no início da década de 1970, minha inserção como docente no curso de Ciências Sociais, na década de 1980 e, na década seguinte, a entrada para a área de Antropologia. Estas memórias se enriquecem com depoimentos de precursores da disciplina, alguns deles atuantes até hoje. Antes disso, no entanto, descreverei em rápidas pinceladas o contexto histórico-cultural da emergência da Antropologia entre nós.

Os anos de 1930 em Goiás, seguindo a tendência interpretativa sobre as transformações da sociedade brasileira adotada principalmente por cientistas sociais e historiadores, são considerados como marco da transição que separa o universo tradicional do moderno. No caso goiano, o tradicional foi concebido como penúria e decadência ${ }^{1}$ num rol de descrições que passa, entre outras coisas, pelo isolamento da região, pelo atraso identificado com o latifúndio e com a produção campone-

1. Um exemplo dessa concepção está num artigo publicado, em 1963, em um suplemento literário de um jornal local, e republicado em 1971, em forma de coletânea, cujo autor era um professor de antropologia do então Departamento de Antropologia e Sociologia da UFG: "Sem dúvida, as características feudais e agrárias da cultura goiana amarraram o progresso por intermédio do insulamento, da rotina, do tradicionalismo. Uma das forças responsáveis pelas mudanças culturais é o contato, a intercomunicação, a difusão. Ora, antes de 30, cada comuna goiana vivia isolada, ensimesmada, empelicada, ou envolvida por um meristema de tradições impermeável às influências externas. Os contatos eram superficiais e intermitentes, no ritmo lento do carro-de-boi, ou no passo estradeiro de comitivas. De quando em quando, aparecia o cometa, vendendo a mercadoria produzida nas cidades litorâneas, ou o juiz de direito, o médico, o advogado, ou o padre, que vinham de fora, quando não fossem filhos da terra que regressavam dos estudos, depois de longa ausência" (Neiva, 1971, p. 99). Atualmente a reflexão sobre o estigma da decadência de Goiás se localiza nos textos dos viajantes europeus, que perscrutaram o interior do Brasil e a Província de Goyaz no século XIX, a origem dessa identidade negativa atribuída aos goianos. Ver Doles e Nunes (1992) e Chaul (2002). 
sa de base familiar, com o sistema político fundado no poder de coronéis, com a tacanhez do modo de vida sertanejo que emoldurava indiferenciadamente o lavrador e o dono da terra, o faiscador de ouro e diamantes e o soldado, o comerciante andarilho e o tropeiro, e, em suma, com as formas de sociabilidade repetitivas dos inumeráveis festivais religiosos, da sucessão de trabalhos, estações e ciclos de vida. ${ }^{2}$

O conjunto desses quadros ou de partes deles descreve imagens do sertão que têm servido para uma construção simbólica da identidade regional, construção esta que, ora negando ora afirmando o caráter híbrido da configuração que nos singulariza como goianos, abrange desde a produção literária regionalista até as interpretações acadêmicas da historiografia e das ciências sociais locais.

O século XIX em Goiás é prefigurado como o tempo da decadência que sucedeu ao efêmero período da mineração de ouro, iniciado em 1722, mas já decadente no final daquele século, quando começaram a se apresentar os primeiros sinais de esgotamento das jazidas. Segundo a historiografia, após o auge da exploração aurífera, a população migrou dos pequenos centros urbanos - muitos deles completamente arruinados - e se rarefez pelos sertões, as dilatadas solidões goianas: "Parte da população abandonou o solo goiano e parte dispersou para a zona rural, dedicando-se à criação de gado ou agricultura; costumes e hábitos da civilização branca foram esquecidos em decorrência do isolamento no qual os goianos passaram a viver; ocorreu a ruralização da sociedade e a desumanização do homem" (Palacín; Moraes, 1989, p. 46). ${ }^{3}$

Ainda segundo a historiografia, esse período, marcado pela estagnação econômica que se estendeu por todo o século XIX e invadiu as primeiras décadas do século seguinte, assistiu, entretanto, aos primeiros movimentos rumo à modernização anunciada pela chegada da estrada de ferro e definitivamente instaurada com as repercussões da Revolução de 30 no Estado de Goiás e com a implementação das políticas de integração nacional. Com efeito, a década de 1930 funda uma espécie de tempo mítico, a que são atribuídos alguns dos movimentos que transmudariam, em progresso e modernidade, a paisagem imóvel predo- minante na região de Goiás ao longo de tanto tempo. Planejada para ser expressão da transição que instaurava o novo no lugar do antigo, a transferência da capital da cidade de Goiás para Goiânia foi, secundada pela construção de Brasília no início dos anos 1960, o dado determinante dessas transformações.

É certo que, a partir da década de 1950, Goiânia experimentou um significativo crescimento populacional, que viria, aos poucos, imprimir uma fisionomia urbana na região e produzir novos arranjos da vida social. Nesse contexto de implementação de outros ritmos de trabalho, outros valores e sociabilidades, começam a surgir os primeiros movimentos intelectuais, criam-se faculdades de filosofia e ciências e letras ${ }^{4}$ e são realizadas incursões a campo para coleta de manifestações folclóricas, artefatos indígenas, registros de rituais e de literatura oral, entre outras atividades de cunho "cultural". Os signos do novo que se vinham instituindo nesse quadro urbano, alargado em vários sentidos, pareciam exigir outras modalidades de explicação do mundo. Essa necessidade ensejou, entre nós, a introdução das teorias cultivadas nos círculos letrados dos centros urbanos nacionais e estrangeiros. ${ }^{5}$

Diversificado, então, o universo dos inumeráveis ciclos da vida rural e vislumbrados os sinais da irreversibilidade dos novos padrões de comportamento do mundo urbano, os intelectuais, atuando simultaneamente nos movimentos folclóricos, nos círculos literários e jornalísticos, nos departamentos governamentais e na então incipiente vida acadêmica das primeiras faculdades (posteriormente agregadas às Universidades Federal e Católica de Goiás), eram mobilizados por uma dupla tarefa: de um lado, pela exigência urgente de resgatar e registrar aquilo que imaginavam estar em processo de extinção - as expressões materiais e mentais da população sertaneja, incluindo aí as populações indígenas -; de outro, pelo imenso trabalho de empreender a sistematização de todo o conhecimento produzido no curso do processo de transformação.

Registrar, colecionar, classificar e investigar o que estaria desaparecendo e cedendo lugar a outras arquiteturas da vida coletiva significava dizer, entre

2. Essa indiferenciação, característica das atividades da economia de autossubsistência ou das relações pré-capitalistas, é recorrente nos textos da ficção regionalista goiana. Nesse sentido, é exemplar a novela O trono no morro, de José J. Veiga (1980).

3. O Pe. Luís Palacín foi, por três décadas, professor das Universidades Católica e Federal de Goiás, onde se destacou como pesquisador da História de Goiás, com inúmeras publicações. A tese da decadência, largamente defendida por ele, mas também por grande parte da intelectualidade goiana, impregnou o ensino da História de Goiás no sistema escolar local e a reflexão sobre a região.

4. Um curso de Geografia, mais tarde agregado à então Universidade Católica de Goiás, funcionava desde 1949. Ele foi reconhecido em 1952, coincidentemente com a criação de um curso de História. Nesse mesmo ano, foi instituída a Faculdade de Filosofia, Ciências e Letras, e a UCG foi fundada como Universidade. A UFG foi criada em 1960 e a Faculdade de Filosofia, Ciências e Letras, em 1962. Seus primeiros cursos foram Letras, Pedagogia, Matemática e Física. O curso de Ciências Sociais só foi criado em 1964.

5. É notável o desejo antigo da intelectualidade goiana de contribuir para "civilizar" o sertão, por acreditar que esse movimento prepararia Goiás para integrar o conjunto da nação brasileira. A esse respeito, ver o artigo de Pereira (1995). Sobre a produção das ciências humanas locais e a adoção do desenvolvimentismo como modelo explicativo de Goiás, ver Rabelo (1998). 
outras coisas, que a região já ingressara numa nova ordenação do mundo: as relações sociais e os modos de conceber o mundo transformavam-se agora em objeto de estudo. As diferenciações internas da nova sociedade já se faziam notar até mesmo sob a forma de uma especialização do pensamento, com o aparecimento de métodos e linhas de investigação sobre a vida social cada vez mais variados. Neste contexto, as Faculdades de Filosofia, em Goiânia, "seja sob o modelo da USP ou como o dos Institutos Centrais de Brasília, [eram tidas como] verdadeiros focos de fermentação social contra o tradicionalismo e a estagnação" (Turchi, 1990, p. 12).

Ao mesmo tempo em que os intelectuais participavam do esforço de subtrair o estigma de atraso e isolamento da região, apropriando-se de discursos e de práticas modernizadoras - reproduzindo incessantemente o mito da ruptura com o mundo tradicional -, eles também investiam na elaboração de um sistema de classificação e organização do conhecimento das populações diferenciadas, cujas características e elementos culturais contrastavam frente à instauração do moderno. Animadas pelo afã de resguardar o que era tido como um objeto evanescente, para usar a expressão de Vilhena (1997), inúmeras escavações arqueológicas, expedições etnográficas e folclóricas em Goiás, no atual Estado do Tocantins e no Mato Grosso, foram realizadas com o intuito de coletar, registrar e pesquisar artefatos indígenas, peças arqueológicas e folclóricas, vestígios de populações que se acreditavam distanciadas do projeto modernizador junto com o distanciamento do sertão: indígenas e camponeses e, entre eles, remanescentes de escravos.

Antes mesmo da criação das Faculdades de Filosofia, Ciências e Letras da UFG e da UCG, esse empenho colecionista de objetos da cultura material das populações tradicionais resultava de iniciativas individuais que tinham por finalidade recolher peças para certos acervos particulares. Grande parte desses acervos foi posteriormente doada para o Instituto Goiano de Pré-História e Antropologia da UCG e para o Museu Antropológico da UFG ${ }^{6}$ com a subsequente integração de vários desses exploradores a essas instituições e ao corpo docente dessas universidades. Formando os primeiros núcleos de pesquisa em antropologia, onde atuavam, eles também ensinavam a disciplina no curso de Ciências Sociais, Geografia, História e outros afins.

O Museu Antropológico da Universidade Federal de Goiás foi fundado em 1970, com professores do Departamento de Antropologia e Sociologia (DAS) do então Instituto de Ciências Humanas e Letras da UFG. Visando à pesquisa e à coleta de peças indígenas e registro de manifestações folclóricas, alguns de seus professores realizaram, em 1972, incursões de campo nas seguintes localidades: Parque Nacional do Xingu, Colônia Indígena de São Marcos, Colônia Indígena Meruri, no Mato Grosso; Ilha do Bananal, Jaupaci, Hidrolândia, Cidade de Goiás, Mara Rosa, Orizona e Inhumas, em Goiás. Os trabalhos pioneiros de Arqueologia tiveram início nestas incursões. Em 1975, professores e pesquisadores dos Departamentos de Antropologia e Sociologia, Geografia, Geologia e Química da UFG, em convênio firmado com a Universidade de São Paulo, iniciaram o "Projeto Arqueológico Anhanguera Estado de Goiás", coordenado por Margarida Davina Andreatta do Museu Paulista. ${ }^{8}$

Também no ano de 1972, o Departamento de Antropologia e Sociologia publicou A Carta Arqueológica - Divisão Regional para Cadastramento de Sítios Arqueológicos do Estado de Goiás, ${ }^{9}$ aprovada pelo Instituto do Patrimônio Histórico e Artístico Nacional e a Divisão Regional para o Estudo e Defesa do Folclore no Estado de Goiás ${ }^{10}$ cujo texto contou com a aprovação da Campanha de Defesa do Folclore Brasileiro. Uma pesquisa sobre as técnicas de tecelagem artesanal, realizada de 1972 a 1977, constituiu uma coleção de objetos - instrumentos de trabalho, desenhos de padrões gráficos, tecidos etc. - dos modos de fazer tecidos artesanais, dando início à diversificação das coleções do Museu Antropológico para além de suas coleções de objetos indígenas.

Do meu ponto de vista, a década de 1970 foi o período em que a Antropologia se institucionalizou como disciplina acadêmica, sendo ensinada no curso de Ciências Sociais desde 1964. A criação do $\mathrm{Mu}-$ seu Antropológico, na UFG, respondeu, em grande medida, por esse movimento e deu visibilidade ao conhecimento produzido no campo disciplinar da Antropologia.

6. É o caso do acervo particular do professor Acary de Passos Oliveira, constituído enquanto atuava como sertanista e colaborador do projeto nacional de interiorização do país - como a participação no projeto Rondon, na Fundação Brasil Central (foi o responsável pela operação Bananal), na expedição Roncador- Xingu, na comissão de construção de Brasília - cujas coleções de objetos indígenas foram integradas ao Museu Antropológico da UFG e ao Instituto Goiano de Pré-História e Arqueologia da UCG.

7. A llha do Bananal à época pertencia ao então Estado de Goiás que, em 1988, cede uma parte de seu território para a formação do Estado do Tocantins.

8. Em 1973, o corpo docente de Antropologia era constituído pelos professores Acary de Passos Oliveira, Antônio Theodoro da Silva Neiva, Carlos Rodrigues Brandão, Edna Luisa de Melo, Pe. José Pereira de Maria, Judite Ivanir Breda, Marcolina Martins Garcia e Vivaldo Vieira da Silva.

9. A autoria desse trabalho é das professoras Edna Luisa de Melo e Judite Ivanir Breda, ambas professoras de Antropologia do DAS do curso de Ciências Sociais.

10. O documento é de autoria das professoras Marcolina Martins Garcia e Judite Ivanir Breda, do DAS do curso de Ciências Sociais. 
Mas, ao mesmo tempo em que o ensino e a pesquisa antropológica estavam sendo consolidados tanto na Universidade Federal de Goiás quanto na Universidade Católica, através do Instituto Goiano de Pré-História e Antropologia, as subáreas etnológica, arqueológica e folclórica ensinadas nas várias disciplinas antropológicas do DAS sofreram uma espécie de refração e cederam lugar à hegemonia da Sociologia, que tomou para si a tarefa de explicar a sociedade brasileira e, dentro dela, Goiás e seus processos de mudança, sob a perspectiva do desenvolvimento capitalista. Não que a Antropologia tivesse diminuído o ritmo de suas pesquisas e a quantidade de aulas no currículo do curso. É que, juntamente com as mudanças aceleradas experimentadas com a urbanização da região, vivíamos também sob o terror da ditadura militar e não encontrávamos, nas análises antropológicas daquele período, respostas para os anseios políticos que compartilhávamos, entre eles, a crença de que o movimento estudantil dentro da universidade, aliado aos movimentos sociais de base popular, contribuiriam com a queda do regime militar e a fundação de uma sociedade justa e igualitária.

Por aquele tempo, a crítica marxista, mais afeita à Sociologia e à Ciência Política do que à Antropologia, exerceu um forte apelo aos estudantes de Ciências Sociais, fazendo com que muitos de nós optássemos pela "modernidade" do discurso sociológico em detrimento da Antropologia. Eu me lembro bem de como nós, estudantes dos primeiros anos da década de 1970, recusávamos o conservadorismo que atribuíamos à Antropologia e a toda análise de base funcionalista, e de como nos sentíamos revolucionários por eleger para nosso aprendizado os autores marxistas e o materialismo histórico-dialético que, se não eram também o forte entre os professores de Sociologia, eram buscados nos grupos de estudos, que formávamos como estudantes, para a leitura de O 18 do Brumário de Louis Bonaparte e a Contribuição para a crítica da economia política. Sob a influência das leituras marxistas, fomos conduzidos muito mais em direção a diversas modalidades de militância política que no sentido da pesquisa acadêmica propriamente dita. Para muitos de nós, que estudamos na primeira metade dos anos 1970, era mais importante para a formação do cientista social ler autores marxistas, escrever panfletos, participar de comícios-relâmpagos, fazer e divulgar jornais-murais com recortes de matérias de publicações que viviam sob a mira da censura, do que ler o Ensaio sobre a dádiva ou Estrutura e função na sociedade primitiva.

Dessa forma, contrapor-se ao regime militar imposto ao país, em 1964, era imperativo para a maioria dos estudantes e para alguns professores do curso de Ciências Sociais, criado na UFG no mesmo ano do golpe militar. E, pelo menos entre nós e pela maneira como líamos o mundo àquela época, não vinha da análise antropológica, salvo raras exceções, nenhuma base teórica ${ }^{11}$ sobre a qual pudéssemos fundamentar as nossas opções político-ideológicas e as práticas esquerdistas que nos mobilizavam.

Mas, ainda que os interesses pela Sociologia fossem predominantes entre a grande maioria dos estudantes de Ciências Sociais da UFG, os jovens professores de Antropologia, alguns com formação acadêmica em áreas afins como Geografia, História, Psicologia e Direito, continuavam a ensinar a teoria antropológica, o método etnográfico e a demarcar os campos empíricos da disciplina que, entre nós, eram voltados para o estudo e a compreensão dos modos de vida do homem do Centro-Oeste. Por essa época também, alguns professores saíram de Goiânia para cursar pós-graduação noutras cidades, enquanto outros, já com mestrado concluído, alguns vindos de fora, ingressaram no curso, ampliando o quadro docente de Antropologia em Goiás. ${ }^{12}$

Em seguida ao término da graduação em Ciências Sociais, em meados dos anos 1970, ingressei como professora de Sociologia na Universidade Católica de Goiás e, em 1978, iniciei minha carreira na UFG, como professora de Métodos e Técnicas em Ciências Sociais e Sociologia. Em 1980, um grupo de professores dos Departamentos de Letras, de Geografia, de Comunicação e de Ciências Sociais criou o Centro de Estudos da Cultura Popular (CECUP), que, embora oficialmente fosse interdisciplinar, realizou pesquisas e estudos antropológicos na região. A experiência de pesquisa desse grupo veio a revelar, algum tempo depois de o grupo ter se desfeito, algumas vocações antropológicas, transformando semiólogos, sociólogos e professores de Letras em antropólogos. Minha participação no CECUP - e no projeto de pesquisa "Biblioteca da vida rural brasileira" - foi fundamental nesse redirecionamento, quando me inscrevi, em 1986, no mestrado em Antropologia

11. Pelo menos para minha turma que iniciou a graduação em 1971, a exceção eram as aulas de Psicologia Social I e II, do professor Carlos Rodrigues Brandão - que acabara de defender seu mestrado em Antropologia Social na Universidade de Brasília - onde líamos, entre uma e outra incursão em campo para estudar hábitos alimentares de camponeses, os dois volumes de A ideologia alemã, de Marx e Engels.

12. Em meados dos anos 1980, ingressaram na área de Antropologia do Departamento de Ciências Sociais as arqueólogas Dilamar Cândida Martins e Irmhild Wust, e os antropólogos sociais Marco Antônio Lazarin, Custódia Selma Sena, Cintya Maria Costa Rodrigues e Maria Luiza Rodrigues Souza. Já fazia parte de seu corpo docente a professora Denise Farah. A professora Mari Nazaré Baiocchi, precursora dos estudos dos quilombos goianos de Cedro e Kalunga, também integrou por algum tempo o Departamento de Ciências Sociais, mas sua atuação como professora e pesquisadora teve pouca repercussão na formação de estudantes de Ciências Sociais, pois grande parte do seu tempo como professora da UFG fora cumprido em instâncias administrativas e prestando serviço em outros lugares, como o Mestrado em Direito Agrário na Faculdade de Direito. Somente em meados dos anos 1990, a professora Joana Aparecida Fernandes da Silva ingressa na área. 
Social, na Universidade de Brasília. Ao retornar da licença para cursar o mestrado, requeri minha transferência da área de Sociologia para a de Antropologia.

Nos anos 1980, por iniciativa do Museu Antropológico da UFG, foram ministrados três cursos de especialização em Antropologia, ${ }^{13}$ que vieram reafirmar importância da disciplina no curso de Ciências Sociais da UFG. A partir desses cursos - e também por termos incursionado na pesquisa em Cultura Popular, no CECUP - alguns de nós imprimimos uma reorientação à nossa vida acadêmica e terminamos optando pela pós-graduação em Antropologia. ${ }^{14}$

Por esse tempo, a UFG logrou ampliar os seus quadros docentes, contratando professores e pesquisadores antropólogos oriundos de outras regiões do país, muitos deles já titulados; a estes, logo passaram a fazer companhia os acadêmicos egressos dos próprios quadros da universidade, estimulados por políticas específicas de qualificação a tomar parte nos programas de pós-graduação em Antropologia Social.

O crescimento do número de professores vindos de outros lugares, com formação em diferentes universidades, significou a diversificação e ampliação das temáticas a serem investigadas. Dos anos 1990 para cá não eram apenas as populações indígenas, os legados arqueológicos e o material folclórico das populações iletradas que constituíam os objetos de estudo das pesquisas realizadas. Enfoques cada vez mais diversificados sobre "objetos" os mais variados, advindos especialmente do universo urbano, impunham-se, por sua relevância, à investigação antropológica.

Com a qualificação do seu quadro docente, novas demandas foram postas para a Antropologia da UFG, na entrada no século XXI. O grupo de antropólogos, ainda que marcado por diferenças inter- nas de várias ordens, iniciou um movimento com a finalidade de fortalecer e ampliar o campo de atuação da disciplina, não só dentro da universidade, mas também buscando projetar suas reflexões para fora $\mathrm{da}$ vida acadêmica ou ainda buscando alcançar interlocuções além dos limites regionais. Entre outras ações, nesse sentido, se destacam: a curadoria da exposição de longa duração do Museu Antropológico, "Lavras e louvores"15 que, usando as possibilidades comunicativas de uma exposição museológica, alargou a reflexão antropológica sobre o sertão e a construção simbólica da região Centro-Oeste, alcançando um público externo à universidade; a realização em Goiânia da $25^{\mathrm{a}}$ Reunião Brasileira de Antropologia, em 2006, num esforço conjunto dos antropólogos da UFG e da UCG, visando ao estabelecimento e fortalecimento de redes nacionais e internacionais entre os pares e à visibilidade do trabalho antropológico realizado na região; a criação do Programa de Pós-Graduação em Antropologia Social; ${ }^{16}$ a participação de vários antropólogos na criação e integração ao corpo docente da Licenciatura Intercultural Indígena; ${ }^{17}$ a criação do bacharelado em Museologia, como iniciativa da área de Antropologia e do Museu Antropológico. ${ }^{18}$ Mais recentemente, a criação de núcleos de pesquisa, vinculados ou não às linhas de pesquisa do mestrado, têm se mostrado atentos às demandas crescentes de interpretação da diversidade cultural brasileira. ${ }^{19}$

Muitas dessas demandas têm convocado os antropólogos aos estudos da sexualidade, do gênero, da raça, dos direitos culturais etc. As áreas de interesse e as temáticas se diversificaram, fazendo com que os estudos antropológicos e a militância dos antropólogos por direitos culturais de minorias e excluídos coincidam em larga medida, o que me leva a concluir

13. O primeiro deles, Métodos e técnicas de abordagem em Etnologia Regional, foi realizado de 4/2/1985 a 28/8/1985; o segundo, Especialização em Antropologia, realizado de 4/11/1985 a 13/12/1985; e o terceiro, Especialização em Antropologia Social, de 31/3/1986 a 18/7/1987. Esses cursos contaram com a presença de professores do Museu Nacional do Rio de Janeiro, da USP, UnB, entre outros centros de pós-graduação consolidados, e reuniu um número significativo de estudantes e profissionais interessados em ingressar na pesquisa antropológica.

14. É o caso do professor Sidney Valadares Pimentel, da professora Telma Camargo da Silva e eu que participamos do CECUP e, com exceção do primeiro, também frequentamos alguns dos cursos de Especialização em Antropologia. O professor Sidney Pimentel, da Faculdade de Comunicação, e a professora Telma Camargo, da Faculdade de Letras, após cursarem doutorado em Antropologia, o primeiro na Universidade de Brasília, e a segunda na City University of New York, passaram a integrar a área de Antropologia do Departamento de Ciências Sociais, em meados dos anos 1990 .

15. Respondem pela cocuradoria da exposição Custódia Selma Sena e Nei Clara de Lima, a convite da então diretora do Museu Antropológico Dilamar Cândida Martins.

16. Embora a discussão da estrutura do mestrado em Antropologia Social integrasse todo o grupo de antropólogos da então Faculdade de Ciências Humanas, o empreendimento do projeto, a redação e as negociações foram capitaneadas por Custódia Selma Sena e Roberto Cunha Alves de Lima.

17. A criação desse curso se deveu à iniciativa da Faculdade de Letras, mas desde o início contou com a participação de antropólogos do Departamento de Ciências Sociais, Marco Antônio Lazarin e Joana Aparecida Fernandes da Silva. Um tempo depois, Mônica Pechincha e Alexandre Ferraz Herbetta também se juntaram ao grupo.

18. A ideia foi capitaneada inicialmente pelos professores Marco Antônio Lazarin, Maria Luiza Rodrigues Souza e Nei Clara de Lima que formaram a comissão de elaboração do projeto pedagógico do curso em 2007, mais tarde integrada pela museóloga Manuelina Maria Duarte Cândido.

19. São eles: Núcleo de Estudos e Pesquisas em Gênero e Sexualidade (Ser-Tão); Núcleo de Estudos de Antropologia, Patrimônio, Memória e Expressões Museais (NEAP); Núcleo de Etnologia Indígena (IMPEJ); e Núcleo de Estudos e Pesquisas em Antropologia Audiovisual (NEPAA). 
que, se nos tempos pioneiros, a "identidade política" da disciplina era considerada conservadora, nos dias atuais, os estudos direcionados às expressões das subjetividades contemporâneas, por exemplo, se fazem acompanhar de toda forma de militância: colaboração com movimentos sociais e manifestações por direitos sociais e étnicos, e uso das redes sociais para denúncias e divulgação de ideias.

A construção de contextos de interlocução com os sujeitos das pesquisas tem trazido, para o interior da disciplina, questões éticas e políticas cada vez mais desafiadoras para uma Antropologia que começou, entre nós, postulando o distanciamento das diferenças étnicas em favor da homogeneização da vida moderna. Não só os que foram pensados nas distâncias

\section{Referências}

BRANDÃO, C. R.; RAMALHO, J. R. Campesinato goiano: três estudos. Goiânia: Ed. UFG, 1986.

CHAUl, N. F. Caminhos de Goiás: da construção da decadência aos limites da modernidade. 2. ed., Goiânia: Ed. UFG, 2002.

DOLES, D. E. M.; NUNES, H. P. Memória da ocupação de Goiás na primeira metade do século XIX: a visão dos viajantes europeus. Ciências Humanas em Revista - História, Goiânia, v. 3, n. 1-2, jan./dez. 1992.

COSTA, L. C. B. F. (Entrevista realizada em 4/1/2006). LIMA, N. C. de; SILVA, T. C. da. Proposta de transferência do Centro de Estudos da Cultura Popular (CECUP) para o Museu Antropológico Universitário da UFG. Goiânia, novembro de 1990. (Manuscrito).

LIMA, N. C. de. O Museu Antropológico da UFG e a interlocução com povos indígenas. In: CURY, M. X.; VASCONCELlOS, C. de M.; ORTIZ, J. M. (Orgs.). Questões indígenas e museus: debates e possibilidades. Brodowski: Secretaria de Estado da Cultura; ACAM Portinari; Museu de Arqueologia e Etnologia da USP, 2012. (Coleção Museu Aberto).

NEIVA, A. T. da S. Um estudo antropológico: a formação temporais e geográficas da vida urbana, como índios e quilombolas, são interlocutores contemporâneos, como também os diferentes grupos que reivindicam identidades e direitos nos inúmeros cenários que emergem da vida coletiva na atualidade.

Relatar esses percursos da Antropologia que construímos no curso de Ciências Sociais da UFG no decorrer de meio século de sua existência, do ponto de vista das minhas memórias, é um exercício de pensar os próprios movimentos da sociedade. Se esse exercício serviu para contar partes da história da disciplina, entrelaçadas com esses movimentos, me dou por satisfeita. O exercício me fez enxergar, pela nostalgia da passagem das coisas e das pessoas, que o tempo é um tecido urdido de memórias, mas também de renovação.

cultural de Goiás. In: MOTA, Á. V. B. da; GOMES, M. (Orgs.). Aspectos da cultura goiana (II). Goiânia: Departamento Estadual de Cultura, Gráfica Oriente, 1971. p. 99.

PALACÍN, L.; MORAES, M. A. de S.'A. História de Goiás (1722-1972). 5. ed. Goiânia: Ed. UCG, 1989.

PEREIRA, E. M. C. M. A construção de nação e região em Goiás, 1830-1945. Ciências Humanas em Revista, Goiânia, v. 6, n. 2, jul./dez. 1995.

RABELO, F. C. E. Desenvolvimento e identidade: parâmetros da reconstrução das ciências sociais e humanas em Goiás. Sociedade e Cultura, Goiânia, v. 1, n. 1, jan./jun. 1998.

TAVEIRA, E. L. de M. (Entrevista realizada em 26/1/2006).

TURCHI, E. Depoimento. Letras em Revista, Goiânia, v. 1, n. 1-2, jan./jun. 1990.

VEIGA, J. J. O trono no morro. In: De jogos e festas. Rio de Janeiro: Civilização Brasileira, 1980.

VILHENA, L. R. Projeto e missão: o movimento folclórico brasileiro, 1917-1964. Rio de Janeiro: Funarte/Fundação Getúlio Vargas, 1997. 


\section{The anthropology routes in Goiás}

\section{Abstract}

From the point of view of the author's memory, this paper narrates some of the institutionalization routes of Anthropology at the Federal University of Goiás, Brazil. Emphases are given to the historical and cultural context of the emergence of anthropological studies as well as the singularities of it in a broader field of the Social Sciences.

Key words: emergence of anthropology at UFG, institutionalization of anthropology in Goiás, memory.

\section{Caminos de la antropología en Goiás}

\section{Resumen}

Este texto narra, desde el punto de vista de la memoria de la autora, algunos de los caminos de la institucionalización de la asignatura Antropología en la Universidad Federal de Goiás. El énfasis se pone en el contexto histórico y cultural de la aparición de los estudios antropológicos y en las singularidades de la disciplina en el curso de Ciencias Sociales.

Palabras clave: surgimiento de la asignatura Antropología en la UFG, institucionalización de la asignatura Antropología en Goiás, memoria.

Data de recebimento do artigo: 30/10/2014

Data de aprovação do artigo: 18/12/2014 